\title{
On the Importance of Formulaic Sequences in EFL Teaching of Writing
}

\author{
LIU Wei, SONG Yan \\ Northeastern University, Shenyang, China
}

\begin{abstract}
Formulaic sequences, also called chunks, cover a wide range of multi-word units which are stored and retrieved as whole from memory. They play a vital role in daily communication, contributing to the ease, fluency, and appropriateness with which someone speaks or writes. This essay discusses the characteristics and functions of FSs in written discourse, which aims to give insights into effective EFL (English as a foreign language) teaching of writing.
\end{abstract}

Keywords: formulaic sequence, English writing, characteristics, function

\section{Introduction}

In recent years, there is a wide spread concern over the significant role of formulaic sequences in language teaching and learning. Beginning with analysis of the theoretical basis of formulaic sequences, this essay is intended to make an overall review of the studies on FSs and related researches on the role of FSs in written course. Though detailed analysis of the characteristics of FSs in written discourse, the essay illustrates the importance of integrating FSs into English writing class, from which students could benefit a lot.

\section{Theoretical Basis for FSs (Formulaic Sequences)—Dual-Model System}

Formulaic sequence is mainly based on the theory of dual system. Skehan (1998) adopted dual-coding or dual-mode system to illustrate language learning and production. Language is on the one hand a rule-based analytic system which is composed of words and limited grammatical rules and it is relatively closed. Under this system, "rules have primary importance, and language is produced by filling out these rules with lexical exponents since the priority is to construct sentences which conform to the grammar of the language in question" (Skehan, 1998, p. 89). On the other hand, it is exemplar-based formulaic system which consists of the formulaic sequences with communicative function. "The rule-based system is likely to be parsimoniously and elegantly organized, with rules being compactly structured" (Skehan, 1998, p. 89). It has its advantages in that it enables maximum creativity and flexibility and demands little on memory storage. But its shortcomings are not far to reach: The operation will lead to a heavy processing burden on the part of both speakers and listeners during ongoing language use. In contrast, the exemplar-based system, with numerous relatively fixed phrases stored in memory in advance which function as integrated wholes, does not require excessive internal computation, thus can contribute to the accuracy, appropriateness, and fluency of language communication. He further points out

LIU Wei, lecturer, master, Foreign Studies College, Northeastern University.

SONG Yan, lecturer, master, Foreign Studies College, Northeastern University. 
that either the exemplar-based system or rule-based system has its respective advantages and disadvantages in that "the former emphasizes representation at the expense of processing, while the latter does the reverse" (Skehan, 1998, p. 89). Being separated, neither works perfectly. What matters is to explore a way in which the two systems might work harmoniously together.

Many linguists have noticed the dual system of langue and they have adopted different terms in their studies. Several versions of dual-mode system have been proposed from the perspective of psycholinguistics.

Having observed the strong patterning in the co-occurrence of words, Sinclair (1987) proposes two principles - the open-choice principle and the idiom principle. The open-choice principle,

Is a way of seeing language text as the result of a very large number of complex choices. At each point where a unit is completed - a word or a phrase or a clause - a large range of choice opens up, and the only restraint is grammaticalness. (Schmitt \& McCarthy, 2002, p. 42)

Thus this principle is in line with Chomskian view in that it stresses the generativity and creativity of grammatical rules. This principle observes the strong structural patterning of lexis on the basis of their previous frequent occurrence. The two opposites are complementary and coexist, both of which are indispensable to the language system. He further proposes that the idiom principle takes precedence, since "it is natural to communicate by lexical means" (Skehan, 1998, p. 33).

Drawing on the findings from the studies on children's language acquiring process, Cruttenden (1981) claims that language learning on all levels takes place in two stages: a stage of item-learning and a stage of system-learning. Individual items are acquired first and then they are transformed into abstract system. Evidence from his studies enables him to believe that there is a strong possibility that some form of item-learning is an essential prerequisite to any type of system-learning.

Similarly, Wray $(2000,2002)$ has proposed a dual processing model-analytic processing and holistic processing. The former involves the efforts of combining words to form novel linguistic materials while the latter relies on the retrieval of prefabricated strings stored in memory. She further emphasizes that the best deal in communicative language processing can only be achieved "by the establishment of a suitable balance between creative and holistic processes" (Wray, 2000, p. 11).

No matter what terms are used to refer to the modes of language processing, all versions of the dual-mode system are in accordance with each other in illustrating the mechanism of language operations. The two modes of processing are complementary to each other.

Neither the rule-based system nor the exemplar system is ideal separately...the former leads to the development of an open, form-oriented system, while the latter emphasizes meaning, and is less appropriate for underlying system change. The question then becomes one of the exploring how the two systems might work harmoniously together. (Skehan, 1998, p. 89)

The proposal of the dual-mode system challenges the traditional view of putting grammar in the primary place. Language does follow rules, but it is also memory-based. FSs are never marginal in language use and that they play equally important roles as grammar. From the perspective of language learning, the dual-mode system of language use implies that the mastery of the rule-based system is important for using language creatively. However, keeping the balance between the rule-based system and the exemplar-based system is of greater significance for the idiomatic use of any language. 


\section{FSs and Writing}

\section{Characteristics of FSs in Written Discourse}

Nattinger and DeCarrico (2000) make attempts to group formulaic sequences according to their functions in a way that will reflect the requirements of spoken and written language. In retrospect of what we have discussed previously, the functional categories proposed by Nattinger and DeCarrico (2000) are social interactions, necessary topics, and discourse devices. Social interactions are markers describing social relations. Necessary topics are those topics which learners will be asked, or ones that they will need to talk about frequently. Discourse devices are those formulaic sequences that connect the meaning and structure of the discourse.

FSs perform different functions in different kinds of discourses. Conversation, interpreted by listening, is viewed as basically interactional and used for working out social relationships. Therefore, FSs functioning as social interactions and necessary topics play a major role in social conversations. Writing, on the other hand, is featured by being transactional, used for transmitting factual information where discourse devices predominate.

Most of the English writings required of students in Chinese universities mainly have the purpose of transmitting information to the readers rather than maintaining social relationships. Thus they are featured by being transactional. This section will examine the characteristics of the FSs as discourse devices in transactional discourse, with its special focus on their role in organizing overall patterns of the informational content.

According to Nattinger and DeCarrico (2000), written language may be both interactional and transactional. The written discourse, viewed as basically interactional, is used for maintaining social relationship. For example, informal letters, thank-you notes, and personal writing are obviously the most interactional types of writing in that one of their primary purposes is to maintain social relationship. On the other hand, the written discourse, viewed as basically transactional, is used for transmitting information. For example, newspaper articles, reviews, and argumentative writing required of students in a university have the purpose of conveying factual information to the readers. Though the fact that writing can be both interactional and transactional, as a general rule, it deals more with transactional features and requires mainly discourse device FSs because it is the particular function of discourse devices to indicate the overall direction and organization of the informational content of the discourse.

To further examine the essential functions of discourse devices, Nattinger and DeCarrico (2000) introduce two different markers, namely, macro-organizers and micro-organizers. Macro-organizers refer to those FSs acting as "markers of theoverall direction of discourse" and "they signal the organization of high-level information: marking topics, shifts in topics, summary of topics, exemplification, relationships between topics, evaluations, qualifications, and asides" (Nattinger \& DeCarrico, 2000, p. 90). They are mostly transactional.

Macro-organizers can be further divided into two subcategories, namely, global or coordinate macro-organizer (GMO), and local or subordinate macro-organizer (LMO).

GMOs are those which signal the introduction of a topic at the beginning of a discourse, the shift to a new topic, and the summary of a topic. They include topic markers such as what I wanted to talk about was X; let's look at $X$; the first thing is. Examples for topic shifters are that reminds me of $X$; by the way. For summarizers, we usually find the expressions like in a nutshell; to make a long story short; that's all about it. They tell the overall information and serve as basic frames that a complete written discourse is built upon. 
LMOs also mark sequencing or importance of high-level information, but they do so at specific points within the overall framework set by the GMOs. They include markers of exemplification, relation between topics, subtopics, or other subordinate material, evaluative comments, qualification of previous material, andasides (Nattinger \& DeCarrico, 2000, p. 95). The categories under the LMOs are exemplifiers (e.g., for example/instance; how about X?; it's like X), relators (e.g., it has to do with X; not only X but also $Y$; and also), evaluators (e.g., as far as I know; I'm absolutely positive/certain/sure that $X$ ), qualifiers (e.g., it depends on X; it doesn't mean that X), and asides (e.g., Where was I?; I guess that's beside the point). The LMOs are subordinate to global organizers and they contribute to the development and support for the main topics.

Nattinger and DeCarrico (2000) stress the crucial role of macro-organizers in facilitating top-down processing which help shape the listener's or reader's expectations and help him or her to make predictions and inferences about what will follow in the discourse. It is more important because it "enables the listener or reader to by-pass some aspects of bottom-up processing" (Chaudron \& Richards, 1986, p. 113, as cited in Nattinger \& DeCarrico, 2000, p. 103), and because "it allows much faster, more efficient comprehension of the intended message" (Nattinger \& DeCarrico, 2000, p. 103).

In contrast with macro-organizers that mark the high-level information in transactional discourse, micro-organizers are those signals of low-level information often found in interactional discourse, such as $u h$ huh, well, I see, yeah, sure, which are often used simply as pause fillers, and which facilitate bottom-up processing by giving the hearer more time to process a given piece of discourse (Nattinger \& DeCarrico, 2000, p. 104). Micro-organizers are found to be mostly short structures, one-word markers, while macro-organizers turn out to be mostly long, syntactically complex structures, from four to nine words. Since macro-organizers facilitate top-down processing and contribute to the memorization of discourse content, they are what the language learners need most to learn.

\section{Significance of Including FSs in EFL Teaching of Writing}

Many linguistic researchers have attached much importance to teaching FSs in class and among them Lewis, Nattinger, and DeCarrico are influential ones.

Lexical approach, first coined by Lewis, has received growing interest in recent years as an alternative to grammar-based approaches. This approach centers on developing learners' proficiency with lexis or word combinations. Instruction focuses on those prefabricated and ready-made expressions that occur frequently in real language communication rather than on originally created sentences.

Sentences and words are not all that constitute a writing discourse. Those prefabricated and ready-made expressions, which can be retrieved as whole, also play a vital part. Regarding FSs as the smallest teaching units can benefit learners a lot in promoting their writing proficiency. The importance of applying FSs into writing class can be summarized in the following three aspects.

Contributing to the promotion of fluency, authenticity, and vitality in expression. Fluency involves free flowing of language and consistency of meaning. Writing as a process to express one's ideas in written form, involves initially the laying out of the content and later the transferring of the content into detailed expressions. If too much time is consumed at the transferring period, the ready-conceived content in short-term memory will fade, which certainly undermines the fluency of the whole discourse. FSs, a number of word strings stored as individual whole units, can be easily called up and used without the need to compose them on-line through word selection and grammatical sequencing, thus consequently decreasing the language 
decoding pressure in short time. FSs are ready to go with little or no need for further processing, thus learners can greatly save efforts in word reconstruction and selection and gain more time for content organization, which surely guarantees the fluency of expression and consistency of meaning in writing. Furthermore, since FSs are acquired as a whole and stored in long-term memory and characterized by chunk construction and authenticity, flexible applications of them in appropriate contexts will certainly make the expression vivid and native-like instead of sounding odd and Chinglish.

Contributing to the improvement of discourse organizing ability. As we have discussed previously, FSs can function as macro-organizers in signaling the overall direction and marking high level information of the discourse. Macro-organizers are further divided by Nattinger and DeCarrico (2000) into two subcategories, namely, global or coordinate macro-organizer (GMO), and local or subordinate macro-organizer (LMO). GMO refer to topic introducers, topic shifters, and topic summarizers, while LMO are those markers which contribute to the development and support of the main topics including exemplifiers, relators, evaluators, qualifiers, etc. For college students, these macro-organizers play a vital role in concentrating on the main information of the content and holding in hand the overall direction of the written discourse, which enables the top-down processing in writing and greatly contributes to promoting their writing competence. It is found that majority of college English compositions are fraught with problems of fuzzy logic and inconsistency in meaning and syntax. With the help of FSs functioning as macro-organizers, students can start by building the framework of the discourse, get familiar with different organizing structures in different styles of written discourses, and properly apply those markers as topic introducers, developers, modulators, and summarizers in each part. In this way, writing efficiency is attained, ideas are explicitly expressed, and the whole discourse is coherently and logically connected.

Contributing to inspiring students for further success. Many studies on SLA show that foreign language learners usually experience a period of silence. The reasons can be explored in many aspects. One explanation is that they remain silent because they are unable to produce proper sentences to convey messages. Using FSs is the best policy to break the silence. Since FSs are prefabricated chunks with certain pragmatic functions, learners can use them directly in real communication with ease. This can not only reduce the pressure in decoding language in real time, but also make students speak or write fluently without constraints of grammar. English has been found to be a headache for many Chinese students for the reason that though the efforts they have made, they still cannot use English freely and achieve what they expect. FSs can solve this problem by helping students to get instant result from what they have learned, and filling them with a sense of achievement. In this way, their confidence in English study will be boosted to a large extent, which in turn inspires them for further success.

To sum up, it is important and feasible to integrate FSs into English writing class, from which students could benefit a lot.

\section{Conclusion}

In light of the important role of formulaic sequences in writing, it is advisable for teachers as well as the language learners to lay emphasis on the use of FSs. Teaching materials should be adjusted to ensure they are based on authentic language; students should be trained to spontaneously accumulate and apply formulaic sequences in their writings; appropriate teaching methods should be made up with view to facilitating students' better mastery of FSs. It is hoped that the present study offers some new insights into the nature of FSs and 
shed new lights on the future English teaching method and learning strategy, which will help to promote college English writing in an all-round way.

\section{References}

Cruttenden, A. (1981). Item-learning and system learning. Journal of Psycholinguistic Research, 10, 79-88.

Lewis, M. (1993). The lexical approach. Hove: Teaching Training Publications.

Nattinger, J. R., \& DeCarrico, J. S. (2000). Lexical phrases and language teaching. Shanghai: Shanghai Foreign Language Education Press.

Pawley A., \& Syder, H. (1983). Two puzzles for linguistic theory: Native-likes election and native-like fluency. In J. Richards and R. Schmidt (Eds.), Language and communication (pp. 191-226). London: Longman.

Schmitt, N., \& McCarthy, M. (2002). Vocabulary: Description, acquisition and pedagogy. Shanghai: Shanghai Foreign Language Education Press.

Sinclair, J. (1987). Collocation: A progress report. In R. Steele and T. Treadgold (Eds.), Essays in honor of Michael Halliday (pp. 319-331). Amsterdam: John Benjamins.

Sinclair, J. (1991). Corpus, concordance and collocation. Oxford: Oxford University Press.

Skehan, P. (1998). A cognitive approach to language learning. Oxford: Oxford University Press.

Wray, A. (2002). Formulaic language and the lexicon. London: Cambridge University Press.

Wray, A., \& Perkins, M. R. (2000). The functions of formulaic language: An integrated model. Language \& Communication, 20(1), 1-28. 